RASĀYAN J. Chem.

Vol. 13 | No. 4 |2230-2242| October - December | 2020 ISSN: 0974-1496 | e-ISSN: 0976-0083 | CODEN: RJCABP

RJC http://www.rasayanjournal.com http://www.rasayanjournal.co.in

\title{
ADSORPTIVE REMOVAL OF LEAD IONS FROM WASTEWATER USING SORBENTS DERIVED FROM Cedrusdeodara PLANT AND IT'S COMPOSITE WITH Ca-ALGINATE BEADS
}

\author{
Gullapalli Sreelatha, Polavarapu Srineetha, Malireddy Venkata Sai Mohan \\ Reddy and K. Ravindhranath* \\ Department of Chemistry, KoneruLakshmaiah Education Foundation, Green Fields, \\ Vaddeswaram-522 502, Guntur Dt., A.P., India \\ *E-mail: ravindhranath.kunta@gmail.com
}

\begin{abstract}
Three adsorbents based on Cedrusdeodara plant materials are developed for the removal of $\mathrm{Pb}^{2+}$ from water. Cedrusdeodara Stem Powder (CDSP), its $\mathrm{H}_{2} \mathrm{SO}_{4}$-generated active carbon (CDAC) and CDAC-doped Ca-alginate beads (CDAC-Ca-beads), are synthesized and investigated for their sorption abilities for $\mathrm{Pb}^{2+}$ ions. Various extraction conditions are investigated and optimized for the maximum adsorptivities. The sorption capacities are: $10.4 \mathrm{mg} / \mathrm{g}$ for CDSP; $16.8 \mathrm{mg} / \mathrm{g}$ for CDAC; and $25.6 \mathrm{mg} / \mathrm{g}$ for CDAC-Ca-beads. The cumulative sorption of active carbon assisted by Ca-alginate beads, result in higher adsorptivity for CDAC-Ca-beads. Beads show good $\mathrm{Pb}^{2+}-$ adsorptivity in a wide range of pHs: 3.0 to 9.0. This is a marked property as the beads can be used in the treatment of wastewaters having varied $\mathrm{pHs}$. Four-fold excess of co-ions has a marginal effect on the $\%$ removal of $\mathrm{Pb}^{2+}$ ions from water. Thermodynamics parameters indicate that the sorption is endothermic, spontaneous and the nature of adsorption is more chemical than physical or electrostatic. $\triangle \mathrm{H}$ values are in the order: $\mathrm{CDSP}<\mathrm{CDAC}<\mathrm{CDAC}-\mathrm{Ca}-$ $\mathrm{BEADS}$ and so is the increasing order of complexing tendency of $\mathrm{Pb}^{2+}$. Positive $\Delta \mathrm{S}$ values for the sorbents indicate disorder at the solid-liquid interface and it is an ideal condition for $\mathrm{Pb}^{2+}$ ions to cross the solid/liquid surface barrier and hence more adsorptivity. Negative $\Delta \mathrm{G}$ values reflect the spontaneity of the sorption process.Spent CDAC and CDAC-Ca-beads can be regenerated with marginal loss of sorption capacity. Adsorbents developed in this work are successfully applied to treat industrial effluent samples.

Keywords: $\mathrm{Pb}^{2+}$ removal, Adsorbents, Cedrusdeodara stems, Ca-alginate beads, Applications.
\end{abstract}

(C) RASĀYAN. All rights reserved

\section{INTRODUCTION}

Removal of $\mathrm{Pb}^{2+}$ from industrial effluents is one of the interesting areas of pollution control research. ${ }^{1,2}$ The toxicity of lead ions is well known and it is a 'human carcinogen' as per USEPA., Inadequately treated effluents from $\mathrm{Pb}$-based industries is an important pollution source of lead. ${ }^{1-5}$ Even traces of $\mathrm{Pb}^{2+}$, if enters into the water bodies due to ill-treated sewage disposal, gets amplified due to bio-accumulation processes. Lead-free water or a maximum limit of $0.01 \mathrm{ppm}$ are recommended by WHO for human consumption because of its deleterious effects caused to the human beings. ${ }^{3,4}$

Of the various methods of lead removal from water, adsorption methods based on bio-materials especially plants, are proving to be effective, simple, eco-friendly and economical. Further, they are based on materials that are renewable and abundantly available plant sources.

Adsorbents derived from Tamarind $\operatorname{wood}^{6}$, pine cone $^{7}$, pumpkin-seed-shell ${ }^{8}$, coconut shell ${ }^{9}$. MaizeTassesl ${ }^{10}$, Prosopis mimosaceaesawdust ${ }^{11}$, apple juice residue ${ }^{12}$, exhausted coffee grounds ${ }^{13}$, Banana Pseudo stem ${ }^{14}$, Annona squamosa shell ${ }^{15}$ and acid activated clay ${ }^{16}$ are investigated for their efficiency towards the removal of $\mathrm{Pb}^{2+}$ from waste water.

Almondshell ${ }^{17}$, treated rice $\operatorname{bran}^{18}$, treated-Jackfruit leaves ${ }^{19}$, walnut shell powder ${ }^{20}$, and diceriocaryumeriocarpum plant leaves ${ }^{21}$ are also investigated. Calcium-alginate beads doped with active carbon of Caryotaurens seeds ${ }^{22}$ and hydrazine sulphate treated red mud, are investigated for the removal of $\mathrm{Pb}^{2+}$ from industrial. ${ }^{23}$

Rasayan J. Chem., 13(4), 2230-2242(2020)

http://dx.doi.org/10.31788/ RJC.2020.1345997 
RASĀYAN J. Chem.

Vol. 13 | No. 4 |2230-2242| October - December | 2020

This investigation is in this aspect. Our research group is intensively investigating these aspects and found some plant materials or their derivatives having adsorptivities towards metal ions ${ }^{24-30}$. India is endowed with different plants. If plant materials or their derivate are identified for their specific activity towards heavy metal ions, such investigations will turn to be a 'blessing-in-disguise'. These phyto-remediation methods are highly economical, eco-friendly and they are based on abundantly available plant materials. Our trail work reveals that stem powders of Cedrusdeodara plant have adsorptivity for $\mathrm{Pb}^{2+}$ ions. Further, when these stem powders are carbonized with $\mathrm{H}_{2} \mathrm{SO}_{4}$-digestion process, the obtained activated bi-char has enhanced $\mathrm{Pb}^{2+}$ adsorptivity. The inherent disadvantage with these powdered adsorbents is that the filtration of water is slow. The size of the voids between the powdered particles are small and are not helpful for filtration and to make the process quick, pressure-heads are essential. To overcome this disadvantage, investigations are being made with open columns or with beads embedded with the adsorbents. In the present work, the activated bio-char of stems of Cedrusdeodara plant immobilized in Ca-alginate beads, is synthesized. Thus, stem powders of Cedrusdeodara plant (CDSP), their $\mathrm{H}_{2} \mathrm{SO}_{4-}$ generated activated carbon (CDAC) and Ca-alginate beads doped with the activated carbon (CDAC-Caalginate) are investigated for their adsorptivities for $\mathrm{Pb}^{2+}$.

\section{Plant Description}

\section{EXPERIMENTAL}

Cedrusdeodara plant belongs to Plantae family of the plant kingdom and it grows to an average height of 45 meters. It is grown well in western regions of the Himalayas. It is a sacred tree for Hindus and it is known to have medicinal values.

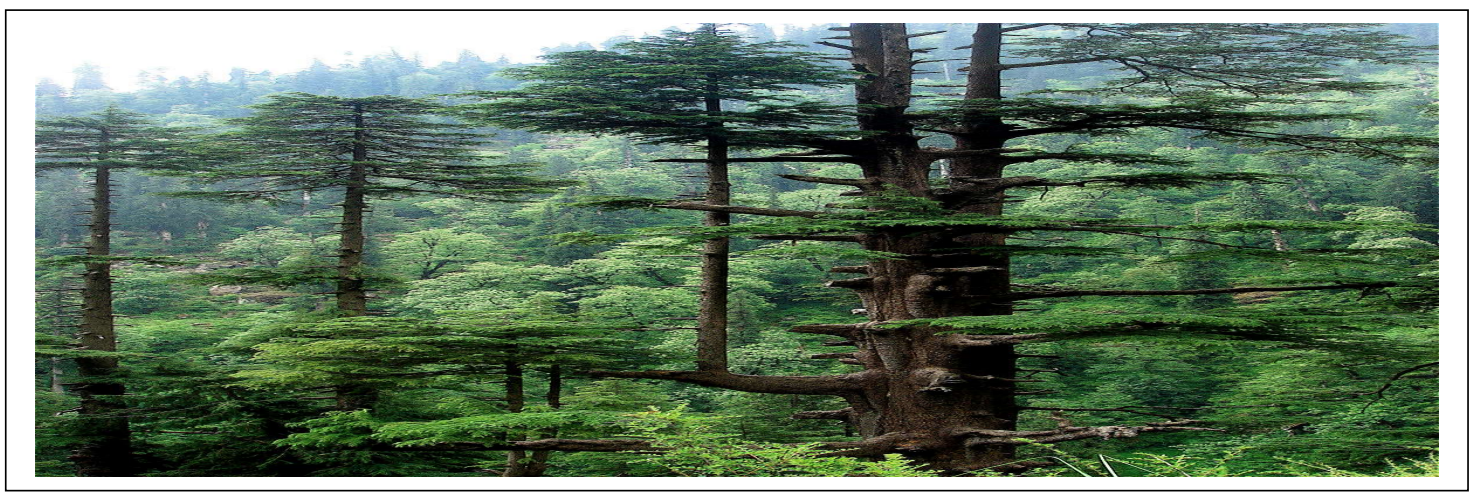

Fig.-1: Cedrusdeodara Plant having Affinity for $\mathrm{Pb}^{2+}$ Ions

\section{Preparation of Adsorbents}

\section{Raw Stem Powder}

The cut Stem pieces of Cedrusdeodara plant were washed with distilled water and hot-oven dried at $102^{\circ} \mathrm{C}$ for two hours. The dried material was crusted to the powder of sieve size less $<75$ microns and preserved in air-tight brown bottles. This material of Cedrusdeodara stem powder is termed as CDSP.

\section{Active Carbon}

Requisite amount of CDSP was taken into a suitable size round bottom flask and to it, the needed quantity of Conc $\mathrm{H}_{2} \mathrm{SO}_{4}$ was added until the material was fully immersed. Then a reflux condenser was set-up. The material in the flask was digested for 3 hours until all the material was completely carbonized. Then the material was taken out from the flask, diluted with water, filtered, washed the activated carbon for neutrality with water, dried at $102^{\circ} \mathrm{C}$ and preserved in an air-tight brown bottle. It is termed as CDAC.

\section{Synthesis of Beads}

Beads doped with CDAC were synthesized by cross-linking Sodium alginate with $\mathrm{Ca}^{2+}$ ion in the same lines of our previous reports for $\mathrm{Ca}$-alginate ${ }^{31}$ and $\mathrm{Zn}$-alginate ${ }^{32}$ beads but with a change in optimum conditions of synthesis.

\section{Method}

$2.5 \mathrm{~g}$ of sodium alginate in $100 \mathrm{ml}$ distilled water was constantly stirred and the temperature of the solution was gradually raised to $70^{\circ} \mathrm{C}$. Then $2.5 \mathrm{~g}$ of CDAC was added while stirring was continued and 
RASĀYAN J. Chem.

Vol. 13 | No. 4 |2230-2242| October - December | 2020

the temperature was maintained at $70^{\circ} \mathrm{C}$ for about 1 hour. The resulting solution was cooled. This solution was added in drop-wise into a previously cooled $\left(10^{\circ} \mathrm{C}\right) 2.5 \% \mathrm{w} / \mathrm{v} \mathrm{CaCl}_{2}$ solution with the aid of a pipette. As the drop oozed out from the tip of the pipette was touched to $\mathrm{Ca}^{2+}$ solution, it got solidified due to cross liking by $\mathrm{Ca}^{2+}$ ions to form beads. Thus obtained beads containing CDAC were allowed to be digested with its mother-liquor for over-night. Then beads were filtered, washed and dried at $102^{\circ} \mathrm{C}$. The beads were termed as CDAC-Ca ${ }^{2+}$-beads.

\section{Chemicals and Reagents}

Analytical Graded pure Chemicals were used in this work. Using double-distilled water, reagents and simulated solutions were prepared. $\mathrm{Pb}^{2+}$ stock solution of concentration: $50.0 \mathrm{mg} / \mathrm{l}$ was prepared and diluted as per the requirement.

\section{Adsorption Studies}

Batch methods ${ }^{33,34}$ were adopted using simulated $\mathrm{Pb}^{2+}$ solutions. Extraction conditions were optimized for the maximum $\mathrm{Pb}^{2+}$ adsorptivity of the three sorbents: CDSP, CDAC and CDAC-Ca ${ }^{2+}$-beads.

\section{Procedure}

$\mathrm{Pb}^{2+}$ ion $(20 \mathrm{ppm})$ solutions of volume: $100 \mathrm{ml}$, were taken into $250 \mathrm{~mL}$ Iodine flasks. Known quantities of CDSP, CDAC and CDAC-Ca ${ }^{2+}$-beads, were added to the solutions. Initial pHs of solutions were adjusted with dil $\mathrm{HCl} / \mathrm{dil} \mathrm{NaOH}$. Then solutions were shaken at $350 \mathrm{rpm}$ in an orbital shaker for the desired time at room temperature. Then the solutions were filtered. The residual content of $\mathrm{Pb}^{2+}$ in the filtrate was estimated using the Atomic adsorption spectroscopic method as described in literature ${ }^{3}$. The instrument used was:AA 500model and it has features: flame absorption; fuel flow rate: 1200 (mL/min); slit: 0.4; Lamp current: $5.0 \mathrm{amp}$; wavelength: $217.00 \mathrm{~nm}$ and High voltage: $416.25 \mathrm{~V}$.

By using the following equations, the adsorbed amounts of $\mathrm{Pb}^{2+}$ ions at equilibrium $\left(\mathrm{q}_{\mathrm{e}}\right)$ and $\%$ removal of $\mathrm{Pb}^{2+}$ were evaluated:

$$
\begin{aligned}
& \mathrm{q}_{\mathrm{e}}=\frac{\left(\mathrm{C}_{\mathrm{i}}-\mathrm{C}_{\mathrm{e}}\right)}{\mathrm{m}} \mathrm{V} \\
& \% \text { removal }=\frac{\left(\mathrm{C}_{\mathrm{i}}-\mathrm{C}_{\mathrm{e}}\right)}{\mathrm{C}_{\mathrm{i}}} 100 \%
\end{aligned}
$$

Where $\mathrm{C}_{\mathrm{i}}=$ initial $\mathrm{Pb}^{2+}$ concentration; $\mathrm{C}_{\mathrm{e}}=$ equilibrium $\mathrm{Pb}^{2+}$ concentration; and $\mathrm{V}=$ volume of solution (in liters); $\mathrm{m}=$ mass of sorbent $(\mathrm{g}) \cdot{ }^{34}$

The influence of solution $\mathrm{pH}$, the dosage of adsorbent, time of contact between the sorbent and $\mathrm{Pb}^{2+}$ solution, initial concentration of $\mathrm{Pb}^{2+}$ solution, co-ions and temperature on the adsoptivities of CDSP, $\mathrm{CDAC}$ and $\mathrm{CDAC}-\mathrm{Ca}^{2+}$-beads were assessed by adopting the above-described method. In assessing the $\mathrm{Pb}^{2+}$ adsorptivities of CDSP, CDAC and CDAC- $\mathrm{Ca}^{2+}$-beads, the targeted parameter was progressively changed while all other parameters were kept at optimum and constant levels. ${ }^{35,36}$ The obtained results are presented in Fig.-2 to 12 and Tables- 1 and 2.

The inference caused by three-fold excess of co-ions was investigated by using simulated solutions having four-fold excess of the concentration of co-ions than $\mathrm{Pb}^{2+}$ ions concentration. The results are presented in Fig.-8 and 9. Regeneration of Spent adsorbents was also investigated and results are depicted in Fig.-12. The adoptability CDSP, CDAC and CDAC- $\mathrm{Ca}^{2+}$ - beads as adsorbents were investigated by applying them to treat real Industrial effluents samples from battery and electroplating industries. The findings are noted in Table-2.

\section{RESULTS AND DISCUSSION}

The extraction conditions were optimized for the maximum adsorptivities of CDSP, CDAC and CDACbeads for $\mathrm{Pb}^{2+}$. Findings and their justifications are presented hereunder. ${ }^{35,36}$

\section{Solution pH (Initial)}

It has a marked influence on the adsorptivities of the sorbents. By varying $\mathrm{pH}$ from 1.0 to 12.0 but keeping at constant levels the other extraction conditions, \% removal of $\mathrm{Pb}^{2+}$ was assessed for each adsorbent. Fig 2 signifies the role of $\mathrm{pH}$.

It is interesting to note that in a wide range of pH: 3.0 to 9.0, CDAC-CA-beads have shown good adsoptivity with a maximum of $85.0 \%$ at $\mathrm{pH}: 7$ (Fig.-2). In the case of CDSP and CDAC, the optimum $\mathrm{pHs}$ are found to be 5.0 and 6.0 respectively. 
RASĀYAN J. Chem.

Vol. 13 | No. 4 |2230-2242| October - December | 2020

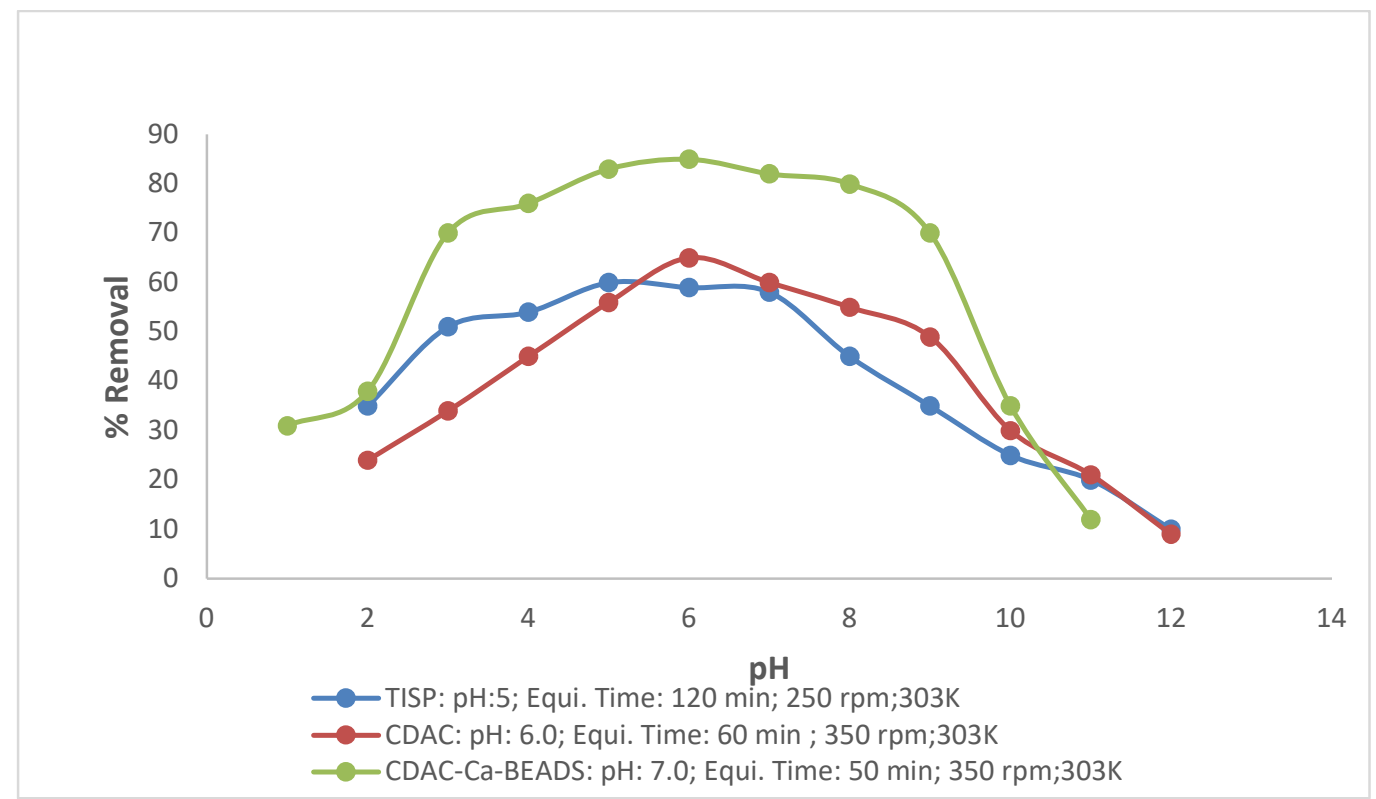

Fig.-2: pH Vs \% removal of $\mathrm{Pb}^{2+}$ Conc. of $\mathrm{Pb}^{2+}: 20 \mathrm{ppm}$

The adsorptivities of sorbents are of the order: CDAC-Ca-beads $>$ CDAC $>$ CDSP. Highest removal of $\mathrm{Pb}^{2+}$ observed are: $60.0 \%$ for CDSP, $65.0 \%$ for CDAC and $85.0 \%$ for CDAC-Ca-beads. CDAC-Cabeads have good adsorptivity in neutral and also in slight basic as well as in acidic solutions. Percentage removal with CDAC-CA-beads as sorbents is: $70.0 \%$ at $\mathrm{pH}: 3.0 ; 76.0 .0 \%$ at $\mathrm{pH}: 4.0 ; 83.0$ at $\mathrm{pH}: 5.0$; $85.0 \%$ at $\mathrm{pH}: 6.0 ; 82.0 \%$ at $\mathrm{pH}: 7.0 ; 80.0 \%$ at $\mathrm{pH}: 8$; and $70.0 \%$ at $\mathrm{pH} ; 9.0$. Above $\mathrm{pH}: 9.0$, adsorptivity of CDAC-Ca-beads falls sharply. With CDSP, removal is : $35.0 \%$ at $\mathrm{pH}: 2.0 ; 51.0 \%$ at $\mathrm{pH}: 3.0 ; 54.0 \%$ at pH: $4.0 ; 60.0 \%$ at $\mathrm{pH}: 5.0 ; 59.0 \%$ at $\mathrm{pH}: 6 ; 58.0 \%$ at $\mathrm{pH}: 7.0 ; 45.0 \%$ at $\mathrm{pH}: 8.0 ; 35.0 \%$ at $\mathrm{pH}: 9.0 ; 25.0 \%$ at $\mathrm{pH}: 10.0 ; 21.0 \%$ at $\mathrm{pH}: 11$ and $9.0 \%$ at $\mathrm{pH}: 12$. With CDAC as sorbent, $\mathrm{Pb}^{2+}$ removal is: $24.0 \%$ at $\mathrm{pH}: 2.0$; $34.0 \%$ at $\mathrm{pH}: 3.0 ; 45.0 \%$ at $\mathrm{pH}: 4.0 ; 56 \%$ at $\mathrm{pH}: 5.0 ; 65.0 \%$ at $\mathrm{pH}: 6.0 ; 60.0 \%$ at $\mathrm{pH}: 7.0 ; 55.0 \%$ at $\mathrm{pH}$ : 8.0; $49.0 \%$ at $\mathrm{pH}: 9.0 ; 30.0 \%$ at $\mathrm{pH}: 10.0 ; 21.0 \%$ at $\mathrm{pH}: 11.0$ and $9.0 \%$ at $\mathrm{pH}: 12.0$.

Sorbents pHzpc values and $\mathrm{Pb}$-speciation will account for these observations. pHzpc values for CDSP, CDAC and CDAC-Ca-beads were found as per procedures available in literature ${ }^{23,24}$. They are 5.1 for CDSP, 6.3 for CDAC and 7.2 for CDAC-Ca-beads, vide Fig.-3. At pHzpc, the sorbent surface has an equal number of positive and negative charges and hence, the surface is neutral. Above pHzpc, the surface is negatively charged when in contact with the solution due to ionization of functional groups viz., $-\mathrm{OH},-\mathrm{COOH}$ etc. Below pHzpc, ionization is less favored; at very low solution $\mathrm{pHs}$, surfaces may acquire a 'positive' charge due to protonation. The nature of $\mathrm{Pb}$ (II) ions in the solution depends on $\mathrm{pH}$ of solution: $<\mathrm{pH} 4: \mathrm{Pb}^{2+}$; $\mathrm{pH}: 4$ to $6: \mathrm{Pb}^{2+} / \mathrm{Pb}(\mathrm{OH})_{2}(\mathrm{~s}) / \mathrm{PbOH}^{+}$and $\mathrm{pH}: 7$ to $12: \mathrm{Pb}(\mathrm{OH})^{3-}$ and $\mathrm{Pb}(\mathrm{OH})_{4}{ }^{2-}{ }^{2}{ }^{-37}$ It is interesting to note the nature of curves in Fig.-3 depicted between $\mathrm{pH}$ and $\%$ removal. With CDACCa-beads, a symmetrical hump is noted in a wide range of $\mathrm{pH}: 3$ to 9 with good adsorptivity. This symmetrical hump indicates a kind of surface complex formation between $\mathrm{Pb}^{2+}$ and the functional groups of CDAC-Ca-beads. Though to a less extent, such curves are observed for CDSP as well as for CDAC. At high $\mathrm{pHs}$ (basic conditions), the adsorptivities for the three sorbents are low. In basic conditions, the surface of the adsorbents, as well as the $\mathrm{Pb}(\mathrm{II})$ species $[\mathrm{Pb}(\mathrm{OH}) 3-$ and $\mathrm{Pb}(\mathrm{OH}) 42-]$, are negatively charged and hence, they experience repulsion; so less adsorptivity. At very low $\mathrm{pHs}, \mathrm{H}^{+}$will compete with $\mathrm{Pb}^{2+}$ for sorption sites and hence low adsorptivities. Adsorption is found in the $\mathrm{pH}$ range: 3.0 to 9.0 for CDACCa-beads; 3.0 to 9.0 for CDSP and 5.0 to 9.0 for CDAC.

\section{Sorbents Dosages}

The minimum concentration of sorbent required for maximum $\mathrm{Pb}^{2+}$ removal is to be investigated. While changing the concentration from $0.25 / 1$ to $2.5 \mathrm{~g} / 1$ but keeping all other extraction conditions at constant optimum levels as furnished in Fig.-4, the adsroptivities of CDSP, CDAC and CDAC-Ca-beads were investigated. Fig.-4 depicts the results. 
RASĀYAN J. Chem.

Vol. 13 | No. 4 |2230-2242| October - December | 2020

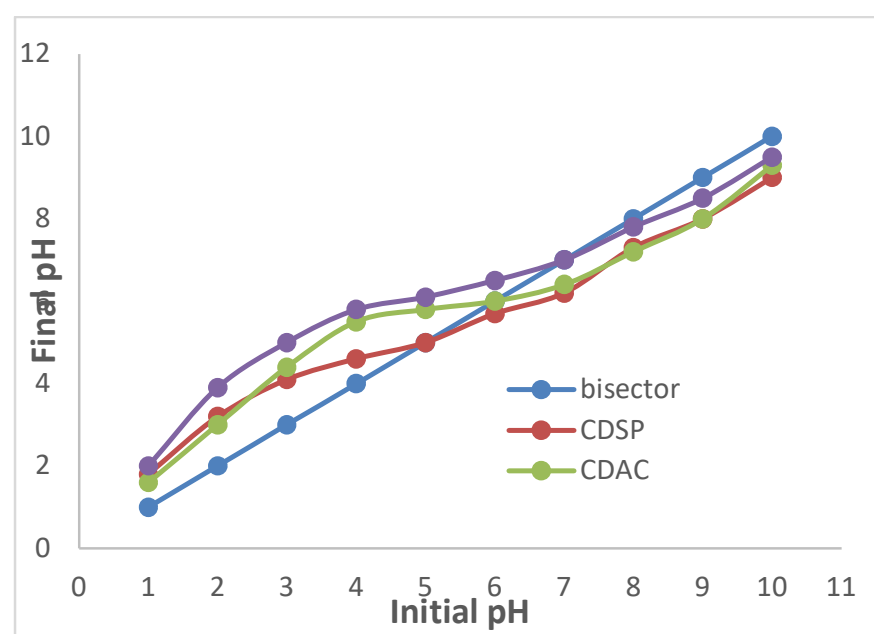

Fig.-3: Evaluation of pHzpc for CDSP, CDAC \& CDAC-Ca-BEADS

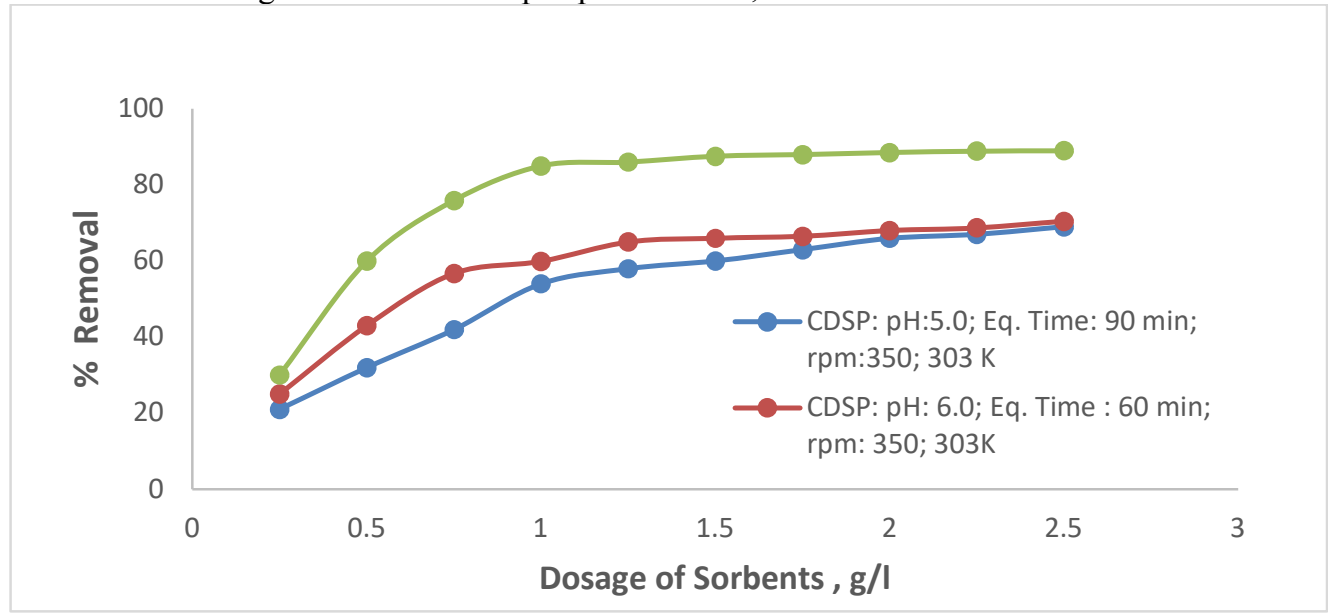

Fig.-4: Effect of Dosage of Adsorbents, Initial Concentration of Pb2+: $20 \mathrm{ppm}$

With the increase in the concentration of CDSP, CDAC and CDAC-Ca-beads, \% removal is progressively increased initially but slows down later; after a certain concentration, \% removal has come to a study state. With CDAC-beads, the \% removal is varied from $30.0 \%$ to $85.9 \%$ as the concentration of CDACCa-beads is changed from $0.25 \mathrm{~g} / 1$ to $0.25 \mathrm{~g} / 1$ to $1.0 \mathrm{~g} / 1$; and above $1.0 \mathrm{~g} / 1, \%$ removal is marginally varied. A similar tendency is shown in the case of CDAC and CDSP. With CDAC, \% removal is increased from $25.0 \%$ to $65.0 \%$ with the increase in concentration of CDAC from at $0.25 \mathrm{~g} / 1$ to $1.25 \mathrm{mg} / \mathrm{l}$; above $1.25 \mathrm{~g} / 1, \%$ removal is marginally varied. With CDSP as adsorbent, as the concentration of CDSP is varied from $0.25 \mathrm{~g} / 1$ to $1.5 \mathrm{~g} / 1, \%$ removal is changed from $21.0 \%$ to $60.0 \%$; with more than $1.5 \mathrm{~g} / 1$, there is a little effect on the $\%$ removal. Plateau regions in curves reflects the steady states: $>1.5 \mathrm{~g} / 1$ for CDSP; $>1.25 \mathrm{~g} / 1$ for CDAC; and $>1.0 \mathrm{~g} / 1$ for CDAC-Ca-beads. An increase in adsorbent concentration naturally increases the active sites and so, progressive increase in the \% removal is noted initially. But later, the proportional increase in \% removal is not observed. Overlapping of active sites and blocking of some path-ways for the migration of adsorbate $\left(\mathrm{Pb}^{2+}\right)$ in sorbent to reach and interact with the active sites, are the causes for the decrease in the rate of \% removal. ${ }^{35,36}$ At the study state, the rate of desorption and the rate of sorption are equal for the adsorbate. These study-states are reached because as the adsorbate $\left(\mathrm{Pb}^{2+}\right)$ concentration is fixed, after a certain dosage, all the $\mathrm{Pb}^{2+}$ ions are engaged with the available sites of adsorbents. This results in no further adsorption and so, the plateau regions in the curves are resulted. ${ }^{22}$

\section{Contact Time}

Another important extraction condition to be optimized is the contact time. It is the time for the sorbent and solution to be in contact with each other at constant agitation conditions at the desired rpm. By varying the time of contact from 10 minutes to 100 minutes but keeping other extraction conditions at 
RASĀYAN J. Chem.

Vol. 13 | No. 4 |2230-2242| October - December | 2020

constant levels as had been noted in Fig.-5, \% removal of $\mathrm{Pb}^{2+}$ from water using the sorbents, CDSP, CDAC and CDAC-Ca-beads, were investigated. The findings are noted in Fig.-5.

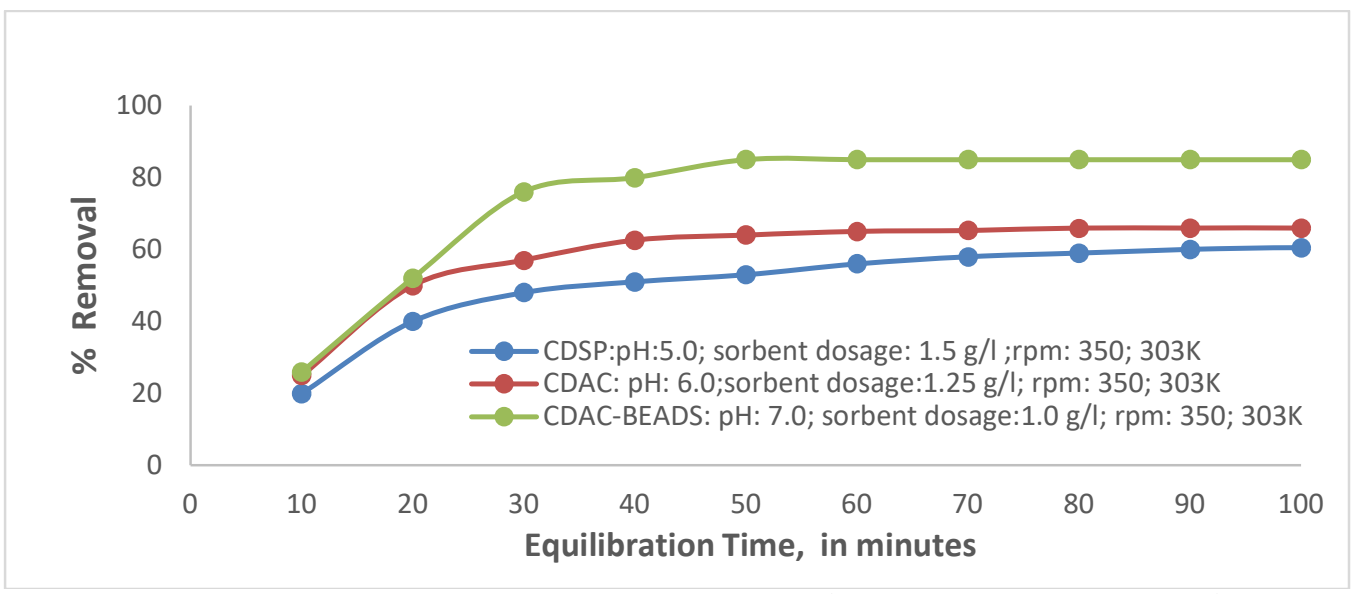

Fig.-5: Effect of Equilibration Time on\% Removal of $\mathrm{Pb}^{2+}$ Initial Concentration of $\mathrm{Pb}^{2+}: 20 \mathrm{ppm}$

The nature of curves indicates that the removal of $\mathrm{Pb}^{2+}$ from water is almost linearly related to agitation time initially but with lapse of time, the \% removal is slow-down and after a certain time, a steady-state is reached. With CDAC-Ca-beads as adsorbent, $\%$ of $\mathrm{Pb}^{2+}$ is found to be $76.0 \%$ at 30 minutes and reached $85.0 \%$ only after 50 minutes and then onwards, \% removal is marginally varied from $85.0 \%$. With CDAC, $52.0 \%$ of $\mathrm{Pb}^{2+}$ is removed within 20 minutes of equilibration but $65 \%$ only after 60 minutes. With CDSP, $48.0 \%$ removal of $\mathrm{Pb}^{2+}$ is observed within 30 minutes and $60.0 \%$ only after 90 minutes.

These findings are as per expectations. Plenty of active sites are available initially and hence, $\%$ removal is more but with the progress of time, active sites are used up and so, adsorption is mellowed. As the added adsorbent is fixed (i.e. $1.5 \mathrm{~g} / 1$ for CDSP, $1.25 \mathrm{~g} / 1$ for CDAC and $1.0 \mathrm{~g} / 1$ for CDAC-Ca-beads), the available active sites are also limited. Hence, after a certain duration, when all the sites are engaged in the adsorption process, further adsorption is not possible and so, a study state is reached. The time needed to reach this study state is 90 minutes for CDSP, 60 minutes for CDAC and 50 minutes for CDAC-Cabeads. ${ }^{24}$

\section{Initial Concentration of $\mathrm{Pb}^{2+}$ (Adsorbate)}

Initial concentration of $\mathrm{Pb}^{2+}$ has profound influence on the adsorptivities of the sorbents. The optimization of this parameter is one of the important features. Maintaining all other conditions at constant levels, initial $\mathrm{Pb}^{2+}$ concentration was varied from $5.0 \mathrm{ppm}$ to $50.0 \mathrm{ppm}$ for finding the adsorptivities of CDSP, $\mathrm{CDAC}$ and $\mathrm{CDAC}-\mathrm{Ca}$-beads for $\mathrm{Pb}^{2+}$. Figure- 6 and 7 depict the observations. Figure- 6 is: \% removal Vs initial concentration and Fig.-7 is : adsorption capacity, $\mathrm{q}_{\mathrm{e}} \mathrm{Vs}$ initial concentration. With the increase in initial concentration of $\mathrm{Pb}^{2+}, \%$ removal decreases while adsorption capacity increases. With CDAC-Cabeads as adsorbent, \% removal is observed to be $89.0 \%$ with $5.0 \mathrm{mg} / 1 ; 88.0 \%$ with $10.0 \mathrm{mg} / 1 ; 85.0 \%$ with $15.0 \mathrm{mg} / 1,84.0 \%$ with $20.0 \mathrm{mg} / 1 ; 76.0 \%$ with $25.0 \mathrm{mg} / 1 ; 72.0 \%$ with $30.0 \mathrm{mg} / \mathrm{l} ; 70.0 \%$ with 35.0 $\mathrm{mg} / 1 ; 64.0 \%$ with $40.0 \mathrm{mg} / \mathrm{l} ; 56.0 \%$ with $45.0 \mathrm{mg} / 1$; and $47.0 \%$ with $50.0 \mathrm{mg} / \mathrm{l}$.

Similarly, as initial $\mathrm{Pb}^{2+}$ concentration is varied from $5.0 \mathrm{mg} / 1$ to $50.0 \mathrm{mg} / 1 ., \%$ removal is decreased from $70.0 \%$ to $32.0 \%$ with CDAC and $65.0 \%$ to $30.0 \%$ with CDSP as adsorbents. But, $\mathrm{q}_{\mathrm{e}}$ is increased.

The adsorption capacity $\mathrm{q}_{\mathrm{e}}$ is increased linearly (nearly) from $2.16 \mathrm{mg} / \mathrm{g}$ to $10.40 \mathrm{mg} / \mathrm{g}$ as the initial concentration is varied from $5.0 \mathrm{mg} / 1$ to $30.0 \mathrm{mg} / \mathrm{l}$ and remains almost constant around $10 \mathrm{mg} / \mathrm{l}$ for CDSP as adsorbent. With CDAC, $\mathrm{q}_{\mathrm{e}}$ is varied from $2.8 \mathrm{mg} / \mathrm{g}$ to $11.8 \mathrm{mg} / \mathrm{g}$ with raise in $\mathrm{Pb}^{2+}$ concentration from $5.0 \mathrm{mg} / 1$ to $25.0 \mathrm{mg} / 1$ and latter remains constant around $12.0 \mathrm{mg} / \mathrm{g}$. With CDAC-Ca-beads, $\mathrm{q}_{\mathrm{e}}$ is varied almost linearly from $4.45 \mathrm{mg} / \mathrm{g}$ to $24.5 \mathrm{mg} / \mathrm{g}$ as the $\mathrm{Pb}^{2+}$ concentrations is varied from $5.0 \mathrm{mg} / \mathrm{l}$ to 35.0 $\mathrm{mg} / \mathrm{l}$ and after that, $\mathrm{q}_{\mathrm{e}}$ almost remains around $25.0 \mathrm{mg} / \mathrm{g}$ even when the initial concentration is increased upto $50.0 \mathrm{mg} / \mathrm{l}$. These findings are as per expectations. With the increase in $\mathrm{Pb}^{2+}$ concentration, $\mathrm{Pb}^{2+}$ ions are forced to migrate towards the surface of adsorbents due to the concentration gradient between the surface layers of sorbent and bulk of the solution. So adsorptivity is progressively increased with an 
RASĀYAN J. Chem.

Vol. 13 | No. 4 |2230-2242| October - December | 2020

increase in $\mathrm{Pb}^{2+}$ concentration. But with a fixed amount of adsorbent (1.5 g/1 for CDSP; $1.25 \mathrm{~g} / 1$ for CDAC and $1.0 \mathrm{~g} / \mathrm{l}$ for CDAC-Ca-beads), there are only a limited number of active sites. When all the sites are exhausted, further sorption is not possible. So, saturation conditions have resulted and hence, plateaus are observed in the curves after $30.0 \mathrm{mg} / 1$ for CDSP, $25.0 \mathrm{mg} / 1$ for CDAC and $35.0 \mathrm{mg} / 1$ for CDAC-Cabeads. ${ }^{25}$

The decrease of $\%$ removal with an increase in the initial concentration of $\mathrm{Pb}^{2+}$ ion can be explained. At low $\mathrm{Pb}^{2+}$ concentrations, plenty of active sites are available for the adsorbate, $\mathrm{Pb}^{2+}$ and so good adsorption. As the concentrations of sorbents are fixed, only a limited number of active sites are available. So, a proportional number of sites needed in-tune with the raise in $\mathrm{Pb}^{2+}$ concentration, are not available. The result is a fall in \% removal with raise in $\mathrm{Pb}^{2+}$ concentration. ${ }^{25}$

\section{Interference of Co-ions}

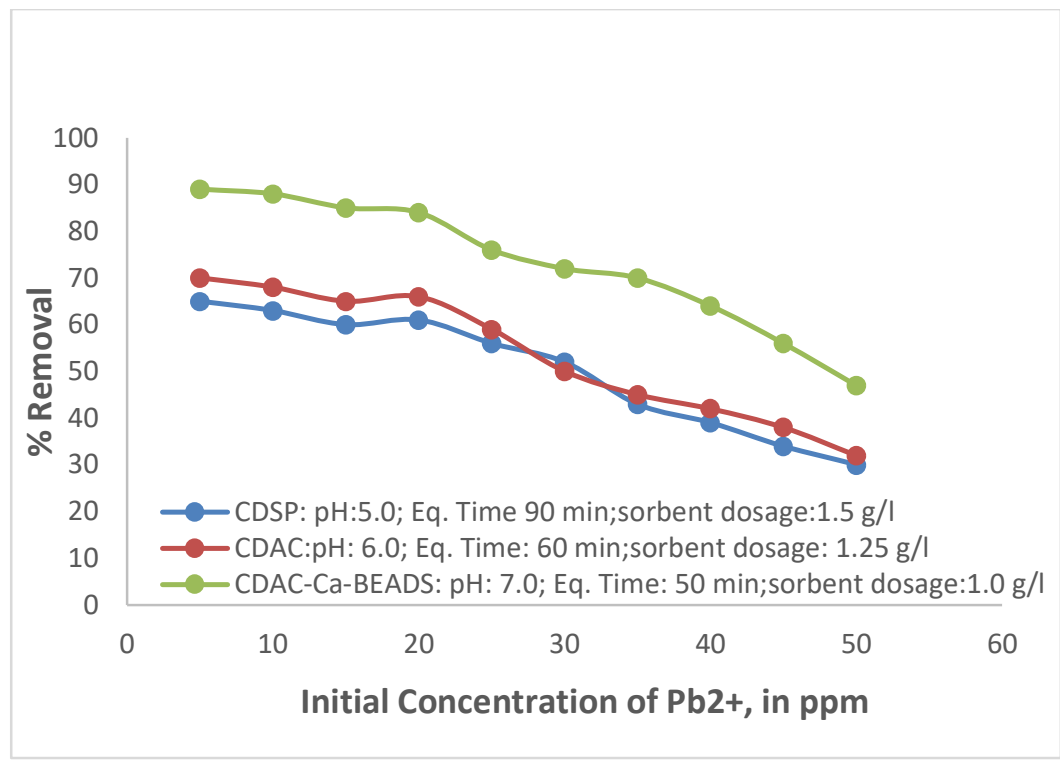

Fig.-6: Initial Conc. $\mathrm{Pb}^{2+} \mathrm{Vs} \mathrm{Pb}^{2+}$ Removal

Interference caused by Co-ions on the extraction of $\mathrm{Pb}^{2+}$ from the water was investigated. For this simulated solutions containing four-fold excess of co-ions to the $\mathrm{Pb}^{2+}$ concentration, were prepared. From these solutions, $\mathrm{Pb}^{2+}$ was extracted using CDSP, CDAC and CDAC-Ca-beads as adsorbents as per the procedures established in this investigation. Figures- 8 and 9 depict the results. From the Figures, it may be inferred that anions namely: $\mathrm{F}^{-}, \mathrm{NO}_{3}^{-}, \mathrm{Cl}^{-}$, phosphate, carbonate and bicarbonate as well as the cations: $\mathrm{Ca}^{2+}, \mathrm{Mg}^{2+}, \mathrm{Zn}^{2+}, \mathrm{Al}^{3+}$ and $\mathrm{Fe}^{2+}$, are marginally interfered with the extraction of $\mathrm{Pb}^{2+}$. This indicates the successful adoptability of procedures for real waters where in multiple co-ions exist along with $\mathrm{Pb}^{2+}$ ions.

\section{Effect of Temperature}

The temperature has a profound effect on the adsorptivities of CDSP, CDAC and CDAC-Ca-beads for $\mathrm{Pb}^{2+}$. The \% removal at $303 \mathrm{~K}, 313 \mathrm{~K}$ and $323 \mathrm{~K}$ were investigated at the optimum extraction conditions as depicted in Fig.-10. It may be inferred from Fig.-10 that as the temperature increases, \% removal of $\mathrm{Pb}^{2+}$ also increases. This indicates the endothermic nature of adsorption. The raise in solution temperature enhances the vibrational motions of surface functional groups pertaining to the adsorbents. The consequence is that more channels are opened for an adsorbate to penetrate deep into the adsorbent's surface layers. Moreover, the kinetic energy of diffusing $\mathrm{Pb}^{2+}$ ions is also increased. These two factors result in enhanced adsorption. ${ }^{31}$

\section{Thermodynamic Studies}

Thermodynamic parameters, change in free energy: $\Delta \mathrm{G}^{0} \quad(\mathrm{~kJ} / \mathrm{mole})$, enthalpy : $\Delta \mathrm{H}^{0}(\mathrm{~kJ} / \mathrm{mole})$ and entropy : $\Delta \mathrm{S}^{0}$ (J/K.mole) were found ${ }^{34,35}$ adopting equations: 
RASĀYAN J. Chem.

Vol. 13 | No. 4 |2230-2242| October - December | 2020

$$
\begin{aligned}
\Delta \mathrm{G}^{0} & =-\mathrm{RT} \ln \mathrm{K}_{\mathrm{d}} \\
\ln \mathrm{K}_{\mathrm{d}} & =\Delta \mathrm{S}^{0} / \mathrm{R}-\Delta \mathrm{H}^{0} / \mathrm{RT} \\
\mathrm{K}_{\mathrm{d}} & =\mathrm{q}_{\mathrm{e}} / \mathrm{C}_{\mathrm{e}} \\
\Delta \mathrm{G}^{0} & =\Delta \mathrm{H}^{0}-\mathrm{T} \Delta \mathrm{S}^{0}
\end{aligned}
$$

Where $\mathrm{K}_{\mathrm{d}}=$ distribution coefficient; $\mathrm{q}_{\mathrm{e}}=$ amount of $\mathrm{Pb}^{2+}$ sorbed; $\mathrm{C}_{\mathrm{e}}=$ equilibrium $\mathrm{Pb}^{2+}$ concentration ; $\mathrm{T}$ $=$ temperature (Kelvin) , $\mathrm{R}$ = gas constant. The results are presented in Fig.-11 and Table-1.

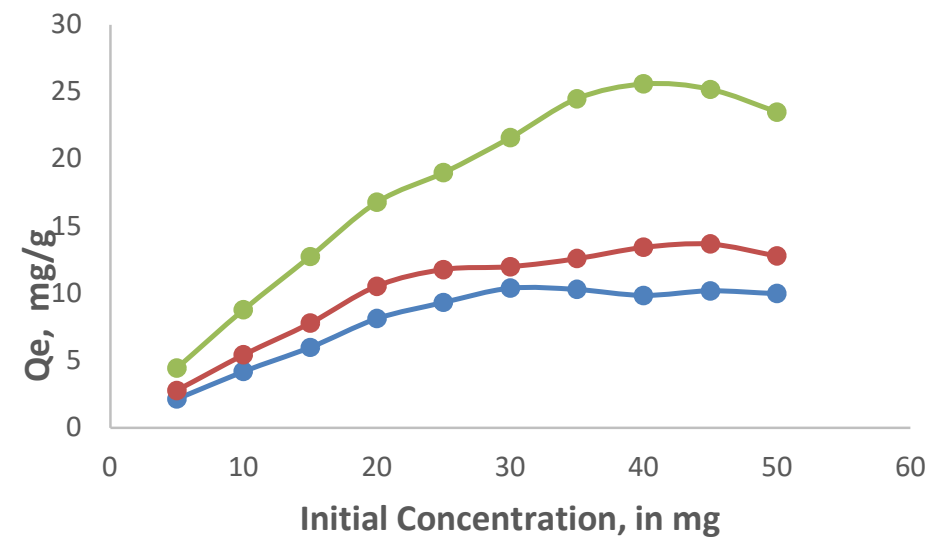

-CDSP: pH:5.0; Eq. Time 90 min;sorbent dosage: $1.5 \mathrm{~g} / \mathrm{l}$ $\longrightarrow$ CDAC:pH: 6.0; Eq. Time :60 min;sorbent dosage: $1.25 \mathrm{~g} / \mathrm{l}$ —CCDAC-Ca-BEADS: pH: 7.0; Eq. Time: 50 min;sorbent dosage:1.0 g/l

Fig.-7: Initial Concentration Vs Sorption Capaity, qe

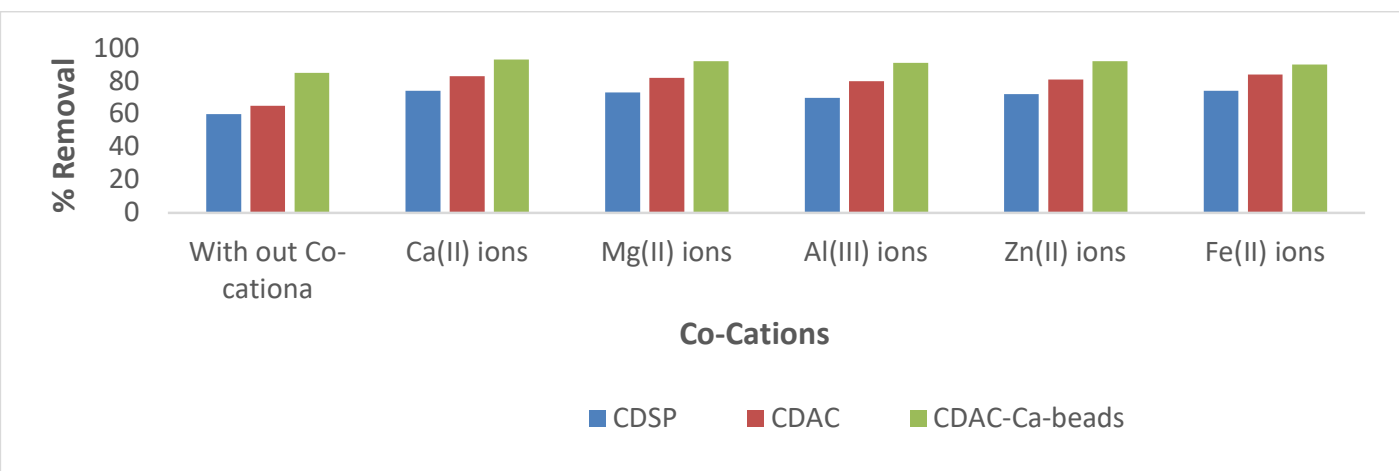

Fig.-8: Interference of Co-cations on the $\%$ removal of $\mathrm{Pb}^{2+}$

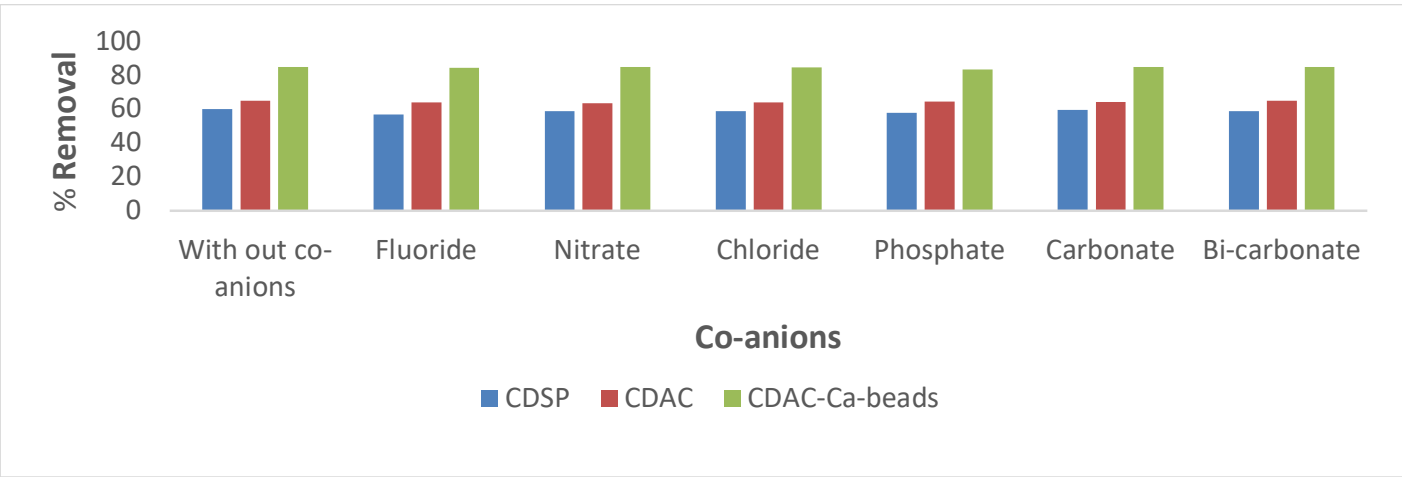

Fig.-9: Effect of Co-anions on the \% Removal of $\mathrm{Pb}^{2+}$ 
RASĀYAN J. Chem.

Vol. 13 | No. 4 |2230-2242| October - December | 2020

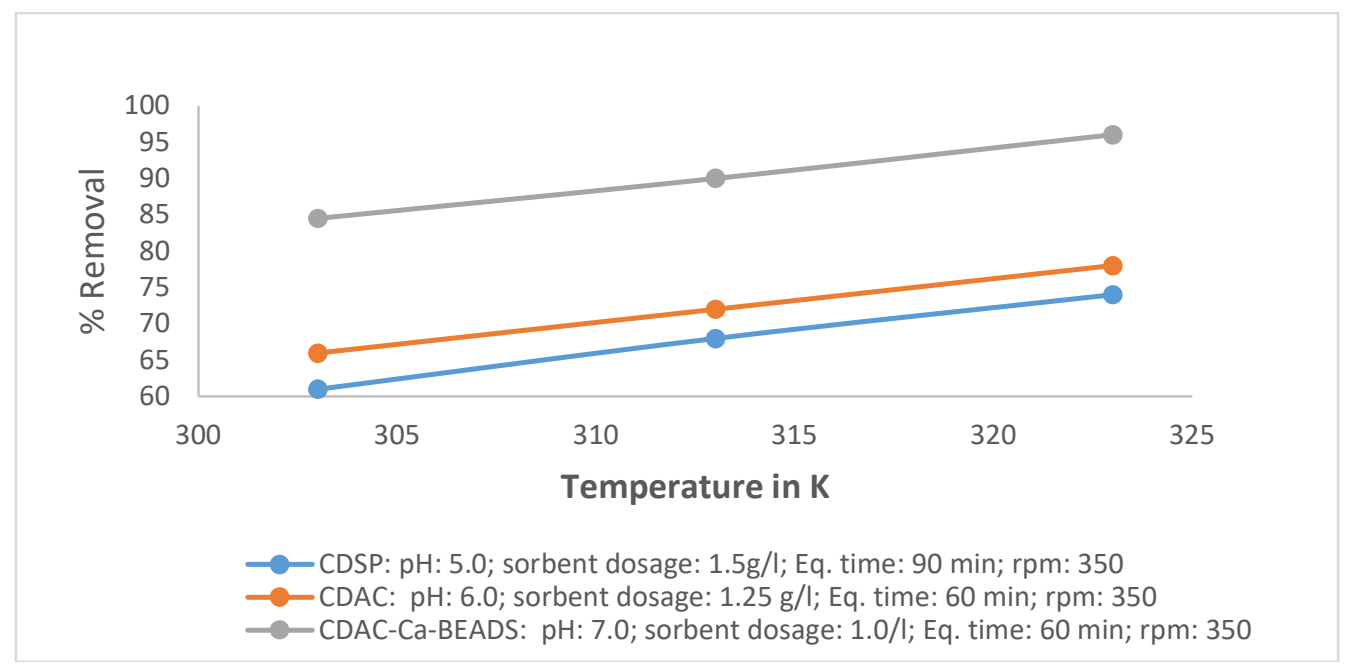

Fig.-10: Effect of Temperature on the Adsoptivities of Sorbents (Initial Concentration of $\mathrm{Pb}^{2+}: 20 \mathrm{ppm}$ )

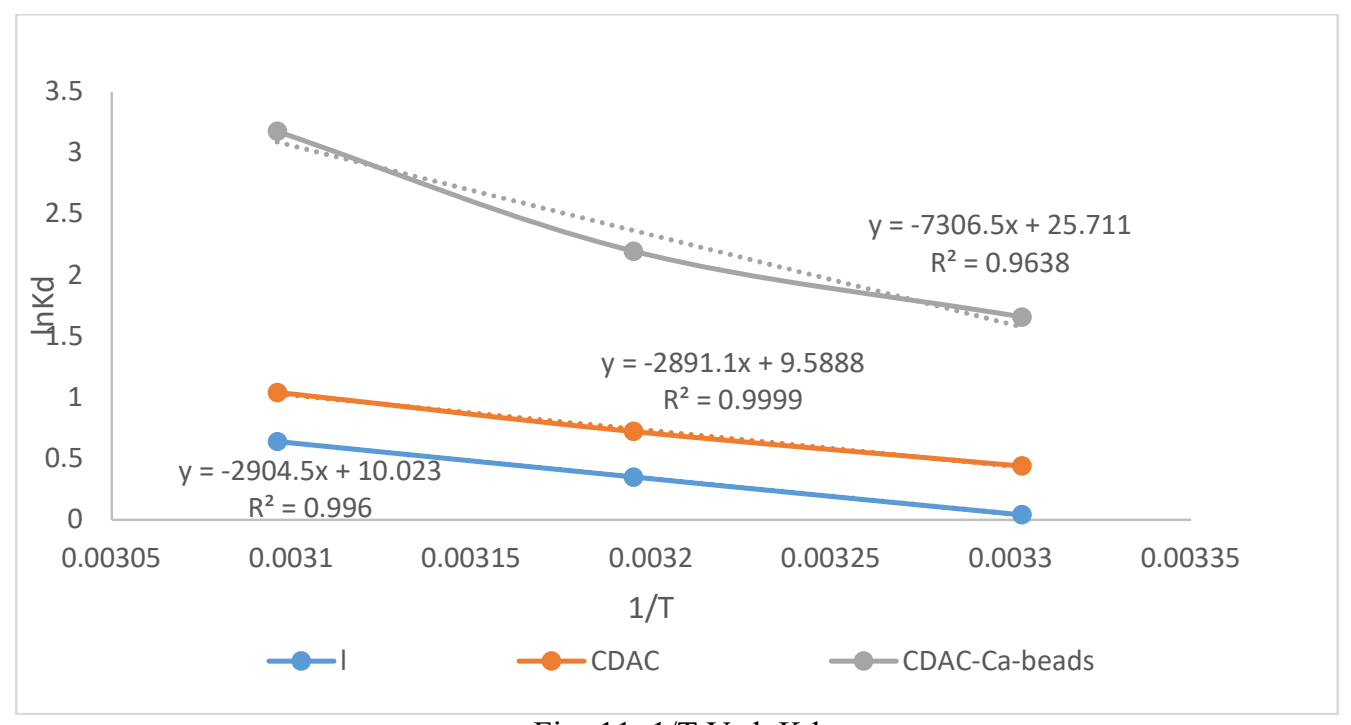

Fig.-11: 1/T Vs $\operatorname{lnKd}$

The salient features of the thermodynamic investigations are:

1. As the $\Delta \mathrm{H}$ values are positive, the nature of adsorption is endothermic for CDSP, CDAC and CDACCa-beads. Further, as the values are more than $24.0 \mathrm{KJ} / \mathrm{mole}$, the nature of the binding of $\mathrm{Pb}^{2+}$ to the surface of the adsorbent is chemical. The $\Delta \mathrm{H}$ value for CDAC-CA-beads is 2.5 folds more than the other two adsorbents. It emphasized that the adsorption is more oriented towards chemical nature in the beads. It is presumed that a kind of surface complexation between the functional groups of adsorbents surface and $\mathrm{Pb}^{2+}$ ions. Further, $\Delta \mathrm{H}$ values increase in the order: $\mathrm{CDSP}<\mathrm{CDAC}<\mathrm{CDAC}$ Ca-BEADS. The chemical nature of binding also increases in the same order.

2. Positive $\triangle \mathrm{S}$ values for $\mathrm{CDSP}, \mathrm{CDAC}$ and $\mathrm{CDAC}$-Ca-beads, reflect disorder at the solid-liquid interface ${ }^{33,34}$ and the values fall in the order CDAC-Ca-beads $>$ CDAC $>$ CDSP. $\triangle \mathrm{S}$ for CDAC-Cabeads is $213.770 \mathrm{~J} / \mathrm{mole}$ and it is nearly 2.5 times higher than the values of CDAC (79.726 J/mole) and $\operatorname{CDSP}(83.336 \mathrm{~J} / \mathrm{mole})$. More is the disorder, higher is the penetration of adsorbate into the adsorbent and hence, more adsorptivity. So, beads having higher $\Delta \mathrm{S}$ values are good adsorbent of $\mathrm{Pb}^{2+}$ among the three sorbents investigated.

3. $\Delta \mathrm{G}$ values are negative for CDSP, CDAC and CDAC-Ca-beads. This emphasizes the spontaneity of the sorption process and it is more in beads than the other two adsorbents from the viewpoint of the 
RASĀYAN J. Chem.

Vol. 13 | No. 4 |2230-2242| October - December | 2020

magnitude of the values. The values indicate attracting forces are good enough to cross the potential barrier at the solid/ liquid interface. ${ }^{22,23}$

\section{Spent CDSP, CDAC and CDAC-Ca-beads Regeneration}

Reuse of the spent sorbents after regeneration assumes importance from the viewpoint of costeffectiveness. As CDSP is a mere raw plant stems powder and is abundantly available, we have not investigated the regeneration of CDSP. But the regeneration of CDAC and CDAC-Ca-beads were investigated by employing various eluting agents such as acids, bases and salts at different dilutions and various experimental conditions.

We observed that $0.1 \mathrm{NHCl}$ was effective. $5.0 \mathrm{~g}$ of spent CDAC or CDAC-Ca-beads were taken in a beaker and was treated with $50.0 \mathrm{ml}$ of $0.1 \mathrm{~N} \mathrm{HCl}$ at room temperature. The adsorbents were filtered, washed with distilled water until the washings were neutral and oven-dried at $102^{\circ} \mathrm{C}$. Thus regenerated $\mathrm{CDAC}$ and $\mathrm{CDAC}-\mathrm{Ca}$-beads were reused for extracting $\mathrm{Pb}^{2+}$ ions from water. The cycles of regenerationcum-reuse were repeated. Figure-12 depicts the findings. It can be inferred from the Fig.-12 that CDAC can be regenerated and reused upto four cycles while CDAC-Ca-beads upto three cycles.

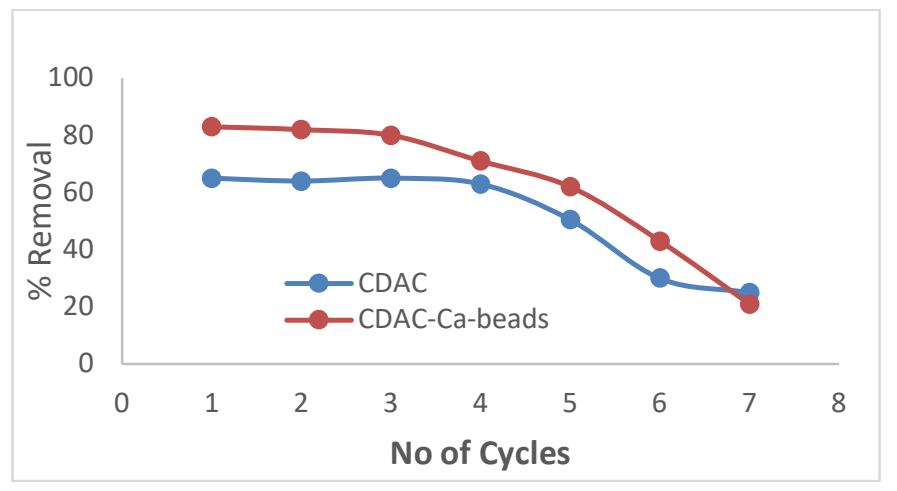

Fig.-12: Spent CDAC and CDAC-Ca-beads: Regeneration and Reuse

Table-1: Thermodynamic Parameters: for $\mathrm{Pb}^{2+}$ Adsorptivity of Adsorbents

\begin{tabular}{|c|c|c|c|c|c|c|}
\hline \multirow[b]{2}{*}{ Sorbent } & \multirow{2}{*}{$\begin{array}{c}\Delta \mathrm{H} \\
(\mathrm{KJ} / \text { mole })\end{array}$} & \multirow{2}{*}{$\begin{array}{c}\Delta \mathrm{S} \\
(\mathrm{J} / \mathrm{mole})\end{array}$} & \multicolumn{3}{|c|}{$\Delta \mathrm{G}(\mathrm{KJ} / \mathrm{mole})$} & \multirow[b]{2}{*}{$\mathrm{R}^{2}$} \\
\hline & & & $303 \mathrm{~K}$ & $313 \mathrm{~K}$ & $323 \mathrm{~K}$ & \\
\hline CDSP & 24.149 & 83.336 & -1.1010 & -1.9350 & -2.7680 & 0.9960 \\
\hline CDAC & 24.038 & 79.726 & -0.11898 & -0.9162 & -1.7135 & 0.9994 \\
\hline $\begin{array}{c}\text { CDAC-Ca- } \\
\text { BEADS }\end{array}$ & 60.749 & 213.770 & -4.0224 & -6.1601 & -8.2978 & 0.9638 \\
\hline
\end{tabular}

\section{Applications}

The new adsorbents developed in this investigation: CDSP, CDAC and CDAC-Ca-beads, were applied to treat real battery and lead platting industry sewage samples. The samples were treated with CDSP (pH: 5.0; sorbent dosage: 1.5g/1; Eq. time: 90 minutes), CDAC (pH: 6.0; sorbent dosage: $1.25 \mathrm{~g} / 1$; Eq. time: 60 minutes) and CDAC-Ca-beads (pH: 7.0; sorbent dosage: $1.0 \mathrm{~g} / \mathrm{l}$; Eq. time: 50 minutes) at room temperature, $303 \mathrm{~K}$. In Table-2, the results are depicted.

The data in Table-2 indicates adsoptivities of the adsorbents for the removal of $\mathrm{Pb}^{2+}$ from samples is in the increasing order: CDSP $(58.4$ to $60.9 \%)<\mathrm{CDAC}(62.7$ to $65.7 \%)<\mathrm{CDAC}-\mathrm{Ca}-\mathrm{BEADS}(81.9$ to $85.3 \%$ ). Hence, CDAC-Ca-beads is a highly effective adsorbent among the three sorbents developed in this work for the removal of $\mathrm{Pb}^{2+}$ from water.

\section{Comparison}

The sorbents developed in this work namely, CDSP, CDAC and CDAC-Ca-beads are compared with some of the important sorbents reported in the literature. Comparison concerning $\mathrm{pH}$ and Sorption capacity are presented in Table-3. 
RASĀYAN J. Chem.

Vol. 13 | No. 4 |2230-2242| October - December | 2020

Table 2: Applications

\begin{tabular}{|c|c|c|c|c|c|c|c|}
\hline \multirow[t]{3}{*}{ Samples } & \multirow[t]{3}{*}{$\mathrm{Ci}^{*}$} & \multicolumn{6}{|c|}{ Adsorbent } \\
\hline & & \multicolumn{2}{|c|}{ CDSP } & \multicolumn{2}{|c|}{ CDAC } & \multicolumn{2}{|c|}{ CDAC-Ca-BEADS } \\
\hline & & $\mathrm{Ce}^{*}$ & $\%$ Removal & $\mathrm{Ce}^{*}$ & $\%$ Removal & $\mathrm{Ce}^{*}$ & \% Removal \\
\hline \multicolumn{8}{|c|}{ Battery Industry Sewages } \\
\hline 1 & 5.5 & 2.2 & 60.0 & 2.0 & 63.6 & 0.85 & 84.5 \\
\hline 2 & 7.5 & 3.1 & 58.7 & 2.8 & 62.7 & 1.1 & 85.3 \\
\hline 3 & 9.0 & 3.7 & 58.9 & 3.3 & 63.3 & 1.4 & 84.4 \\
\hline \multicolumn{8}{|c|}{ Lead- Plating Industry Sewages } \\
\hline 1 & 8.5 & 3.5 & 58.8 & 3.0 & 64.7 & 1.3 & 84.7 \\
\hline 2 & 10.5 & 4.1 & 60.9 & 3.6 & 65.7 & 1.9 & 81.9 \\
\hline 3 & 12.5 & 5.2 & 58.4 & 4.5 & 64.0 & 2.2 & 82.4 \\
\hline
\end{tabular}

$* \mathrm{Ci}=$ initial $\mathrm{Pb}^{2+}$ concentration; $\mathrm{Ce}=$ Equilibrium conc. of $\mathrm{Pb}^{2+}$

* mean value of five determinations; $\mathrm{SD}: \pm 0.39$

Table-3: Comparison of Present Work with Previous Works

\begin{tabular}{|c|c|c|c|c|}
\hline S. No. & Adsorbent & $\mathrm{pH}$ & $\begin{array}{c}\text { Sorption } \\
\text { Capacity, } \mathrm{mg} / \mathrm{g}\end{array}$ & Reference \\
\hline 1 & Pine cone- activated carbon & 6.7 & 27.53 & 7 \\
\hline 2 & $\begin{array}{l}\text { Fluted pumpkin seed shell- active } \\
\text { carbon }\end{array}$ & 7 & 14.286 & 8 \\
\hline 3 & Coconut shell-carbon & 6.0 & 30.0 & 9 \\
\hline 4 & $\begin{array}{l}\text { Maize Tassel based -Activated } \\
\text { carbon }\end{array}$ & 5.4 & 37.31 & 10 \\
\hline 5 & Acid activated clay & 6 & 9.08 & 16 \\
\hline \multirow[t]{2}{*}{6} & Caryotaurens seeds active carbon & 7 & 42.9 & 22 \\
\hline & $\begin{array}{l}\text { Ca-alginate beads impregnated } \\
\text { with Caryotaurens seeds-active } \\
\text { carbon. }\end{array}$ & 7 & 89.6 & 22 \\
\hline 7 & $\begin{array}{l}\text { Hydrazine sulphate-Activated red } \\
\text { mud impregnated in } \mathrm{Ca} \text {-alginate } \\
\text { beads }\end{array}$ & 6.0 & 13.8 & 23 \\
\hline 8 & Waste tire rubber ash & 6 & 22.35 & 38 \\
\hline \multirow[t]{3}{*}{9} & CDSP & 5 & 10.4 & \multirow[t]{3}{*}{ Present work } \\
\hline & CDAC & 6 & 16.8 & \\
\hline & CDAC-Ca-beads & $\begin{array}{l}\text { 7(substantial removal } \\
\text { in } \mathrm{pH} \text { range : } 4 \text { to } 9\end{array}$ & 25.6 & \\
\hline
\end{tabular}

It may be informed from the Table that CDSP, CDAC and CDAC-Ca-alginatte beads have comparable good sorption capacities than many reported in the literature. Especially, CDAC-Ca-beads have shown good sorption capacity than CDSP and CDAC. The beads have shown substantial sorption in a wide range of $\mathrm{pH} 3$ to 9 with a maximum at $\mathrm{pH}$ : 7. This is an important finding as the said adsorbent is effective in slightly acidic, neutral and slightly basic solutions of $\mathrm{Pb}^{2+}$. This wide applicability is desirable in treating waste waters from industries.

\section{CONCLUSION}

- Three adsorbents are developed from the plant materials of Cedrusdeodara plant. Raw fine Cedrusdeodara Stem Powder (CDSP) and $\mathrm{H}_{2} \mathrm{SO}_{4}$-generated active carbon from Cedrusdeodara stem powders (CDAC) are prepared. Further, CDAC-doped Ca-alginate beads (CDAC-Ca-beads), are synthesized by cross-linking Na-alginate with $\mathrm{Ca}^{2+}$. These materials are investigated as adsorbents for their ability in removing $\mathrm{Pb}^{2+}$ from water.

- Various extraction conditions viz., initial $\mathrm{pH}$ of $\mathrm{Pb}^{2+}$ solutions, sorbent concentration, equilibration time, temperature, $\mathrm{Pb}^{2+}$-initial concentration and effect of co-ions have been investigated and optimized for the maximum adsorptivities. 
RASĀYAN J. Chem.

Vol. 13 | No. 4 |2230-2242| October - December | 2020

- The sorption capacities are: $10.4 \mathrm{mg} / \mathrm{g}$ for CDSP; $16.8 \mathrm{mg} / \mathrm{g}$ for CDAC; and $25.6 \mathrm{mg} / \mathrm{g}$ for CDACCa-beads. The cumulative sorption of active carbon assisted by Ca-alginate beads, result in higher adsorptivity for CDAC-Ca-beads.

- Optimum extraction conditions are: $\mathrm{pH}$ : 5.0, sorbent conc.: $1.50 \mathrm{~g} / \mathrm{l}$, eq. time: $90 \mathrm{~min}$. for CDSP; $\mathrm{pH}$ : 6.0, sorbent conc.: $1.25 \mathrm{~g} / \mathrm{l}$; eq. time:60 min for CDAC; and $\mathrm{pH}$ : 7.0, sorbent conc.: $1.0 \mathrm{~g} / \mathrm{l}$, and eq. time: $60 \mathrm{~min}$ for CDAC-Ca-beads.

- The beads show good $\mathrm{Pb}^{2+}$ - adsorptiviy in a wide range of pHs: 3.0 to 9.0. This is a marked property as the beads can be used in the treatment of wastewaters having varied pHs. This feature paves its applicability to industrial effluents.

- Four-fold excess of co-ions has marginally affected the $\%$ removal of $\mathrm{Pb}^{2+}$ ions from water.

- Thermodynamics parameters indicate that the sorption is endothermic, spontaneous and the nature of adsorption is more chemical than physical or electrostatic. Positive $\Delta \mathrm{H}$ values reflect the endothermic nature of the three sorbents. Values $>24.0 \mathrm{KJ} / \mathrm{mole}$ for CDSP and CDAC and $60.75 \mathrm{KJ} / \mathrm{mole}$ for CDAC-Ca-beads, reflect the chemical nature of binding between functional groups $-\mathrm{OH},-\mathrm{COOH}$ of sorbents and $\mathrm{Pb}^{2+}$ ions. This chemical nature is clear especially in the case of beads as the relation curve between $\mathrm{pH}$ and \% removal shows a huge hump in the $\mathrm{pH}$ range: 3 to $9 . \Delta \mathrm{H}$ values are in the order: CDSP $<$ CDAC $<$ CDAC-Ca-BEADS and so is the increasing order of complexing tendency of $\mathrm{Pb}^{2+}$.

- Positive $\Delta \mathrm{S}$ values for all the sorbents show disorder at the solid-liquid interface. ${ }^{24,25}$ The high value of the order of $213.77 \mathrm{~J} / \mathrm{mole}$ for CDAC-Ca-beads, indicate greater disorder and so, an ideal condition for $\mathrm{Pb}^{2+}$ ions to cross the solid/liquid surface barrier and hence more adsorptivities.

- Negative $\Delta G$ values reflects the spontaneity of the sorption process for all the investigating sorbents.

- Spent CDAC can be regenerated and reused upto four cycles while CDAC-Ca-beads upto three cycles with marginal loss of adsorptivities.

- Adsorbents developed in this work are successfully applied and the beads-based sorbent (CDAC-Cabeads) is very effective in removing $\mathrm{Pb}^{2+}$ from industrial effluents.

\section{ACKNOWLEDGEMENT}

The authors thank the authorities of K L University for providing the necessary facilities for this research work.

\section{REFERENCES}

1. F. Fu and Q. Wang, Journal of Environmental Management, 92, 407(2011), DOI:10.1016/j.jenvman.2010.11.011

2. Renata Biela and L. Šopíková, Applied Ecology and Environmental Research, 15(3), 1527(2017) DOI: $10.15666 /$ aeer/1503_15271536

3. American Public Health Association (APHA), Standard Methods for the Examination of Water and Waste Water, 20th ed., American Public Health Association, Washington, DC, 1998.

4. World Health Organization (2011): Lead in Drinking Water, Report No. WHO/SDE/WSH/03.04/09/Rev/1, World Health Organization, Geneva

5. D. Gloag, Sources of Lead Pollution, British Medical Journal (Clinical Research Ed.), 282 (6257), 41 (1981), DOI: $10.1136 / \mathrm{bmj} .282 .6257 .41$

6. Jyoti Kusum Acharyaa, J.N. Sahub, C.R. Mohantycand B.C.Meikap, Chemical Engineering Journal, 149, 249(2009), DOI:10.1016/j.cej.2008.10.029

7. Milan Momčilović, , Milovan Purenović, Aleksandar Bojić, Aleksandra Zarubica and Marjan Ranđelović, Desalination, 276(1-3), 53 (2011), DOI:10.1016/j.desal.2011.03.013

8. A.I. Okoye, P. M. EjikemeOand D.Onukwuli, International Journal of Environmental Science \& Technology, 7(4), 793(2010), DOI:10.1007/BF03326188

9. M.C. Sekhar, Journal of Environmental Science and Engineering, 50(2), 137(2008).

10. Mambo Moyo, Linda Chikazaza, BeniasChomunorwaNyamunda, and UpenyuGuyo, Journal of Chemistry, Volume 2013, Article ID 508934, DOI:10.1155/2013/508934

11. Sadegh Ghasemi and Roya Mafi Gholami, Jundishapur, Journal of Health Sciences, 7(1),e 23498 (2015), DOI: 10.5812/jjhs.23498 
RASĀYAN J. Chem.

Vol. 13 | No. 4 |2230-2242| October - December | 2020

12. Eddy Heraldy, Witri Wahyu Lestari, Diah Permatasari and Devita Dwi Arimurti, Journal of Environmental Chemical Engineering, 6(1), 1201(2018), DOI:10.1016/j.jece.2017.12.026

13. A. Naga Babu, D.S. Reddy, G.S. Kumar, K. Ravindhranath and G.V. Krishna Mohan, G.V.,Journal of Environmental Management,218,602(2018), DOI:10.1016/j.jenvman.2018.04.091

14. Shridhar S. Bagali, Bychapur S. Gowrishankar and Aashis S. Roy, Engineering, 3(3), 409(2017), DOI:10.1016/J.ENG.2017.03.024

15. C.P.J. Isaac and A Sivakumar, Desalination Water Treatment, 51, 7700(2013), DOI: $10.1080 / 19443994.2013 .778218$

16. G. Resmia, G. Santosh, Thampi, and S. Chandrakaran, Environmental Technology, 33 (3), 291(2012), DOI: $10.1080 / 09593330.2011 .572917$

17. E. Pehlivan, T. Altun, S. Cetin and M.I. Bhanger, Journal of Hazardous Materials.,167, 1203(2009), DOI: 10.1016/j.jhazmat.2009.01.126

18. T. Fatima, R. Nadeem, A. Masood, R. Saeed and M. Ashraf, International Journal of Environmental Science \& Technology,10, 1255 (2013), DOI:10.1007/s13762-013-0228-x

19. Jagath K. Premachandra, B.S. Manoj, S.N.P.P.G.P.E. Aberathneand L.H.P.Warnapura. Engineering Research Conference (Mercon), IEEE 2017 Moratuwa.10.1109/MERCon.2017.7980451

20. A. Safinejad, M. Arab Chamjangali, N. Goudarzi and G. Bagherian, Journal of Environmental Chemical Engineering, 5 (2), 1429(2017), DOI:10.1016/j.jece.2017.02.027

21. Joshua N. Edokpayi , John O. Odiyo, Titus A. M. Msagati and Elizabeth O. Popoola, Sustainability, 7, 14026(2015).

22. S. Ravulapalli, and K Ravindhranath, Journal of Environmental Chemical Engineering, 6(4),4298(2018), DOI: $10.1016 / j . j e c e .2018 .06 .033$

23. A. Naga Babu, G.V. Krishna Mohan, K. Kalpana and K. Ravindhranath, Journal of Analytical Methods in Chemistry, 2017, 4650594(2017), DOI:10.1155/2017/4650594

24. Sujitha Ravulapalli and Ravindhranath Kunta, Water Science and Technology, 78(6), 1377(2018), DOI:10.2166/wst.2018.413

25. G.V Krishna Mohan, A. Naga Babu, K. Kalpana and K. Ravindhranath, International Journal of. Environmental Science Technology, 16(1), 101(2019), DOI:10.1007/s13762-017-1593-7

26. P.V. Devi, M. Suneetha and K. Ravindhranath, Asian Journal of Chemistry, 31(10), 2233(2019).

27. Anna Aruna Kumari and K. Ravindhranath, Journal of Chemical and Pharmaceutical Research, 4 (5), 2836(2012).

28. O. Sree Devi and K. Ravindhranath, Indian Journal of Environment Protection, 32(11), 94 (2012).

29. P. Karunasri Meghana, Anna Aruna Kumari , K. Venkata Pravalika, P. Janaki Sriram and K. Ravindhranath, Rasayan Journal of Chemistry 12(1), 338(2019), DOI:10.31788/RJC.2019.1215064

30. Anna Aruna Kumari and K. Ravindhranath, Asian Journal of Water, Environment and Pollution, 15 (1), 23(2018), DOI:10.3233/AJW-180003

31. Ravulapalli, S and K. Ravindhranath, ,Journal of the Taiwan Institute of Chemical Engineers, 101, 50(2019),DOI: 10.1016/j.jtice.2019.04.034

32. A. Naga Babu, G.V. Krishna Mohan, K. Kalpana and K. Ravindhranath, Journal of Environmental Chemical Engineering, 6(1), 906(2018), DOI:10.1016/j.jece.2018.01.014

33. A.R.K. Trivedy, Pollution Management in Industries, Environmental Publications, 2nd Ed., Karad, India, 1995.

34. M. Suneetha, B. Syama Sundar and K. Ravindhranath, International Journal of Environmental Technology and Management, 18(3), 420(2015), DOI:10.1504/IJETM.2015.073079

35. Sujitha Ravulapalli and Kunta Ravindhranath, Journal of Fluorine Chemistry, 193, 58(2017), DOI: 10.1016/j.jfluchem.2016.11.013

36. M. Suneetha, B. Syama Sundar and K. Ravindhranath, Journal of Analytical Science and Technology, 6, 15(2015), DOI: 10.1186/s40543-014-0042-1

37. Albert Cotton F, Wilkinson G, Carlos A. Murillo, Manfred Bochmann, Advanced Inorganic Chemistry, $6^{\text {th }}$ edition, 2007, Wiley-India.

38. H. Z. Mousavi, A. Hosseynifar, V. Jahedand and S. A. M. Dehghani, Brazilian Journal of Chemical Engineering, 27(1), 79 (2010), DOI:10.1590/S0104-66322010000100007

[RJC-5977/2020] 